J. V. Divatia Sameer Jog

\title{
Intensive care research and publication \\ in India: quo vadis?
}

Received: 31 October 2013

Accepted: 17 December 2013

Published online: 18 January 2014

(C) Springer-Verlag Berlin Heidelberg and ESICM 2013

J. V. Divatia $(\square)$

Department of Anaesthesia, Critical Care and Pain,

Tata Memorial Hospital, Dr. E. Borges Marg, Parel,

Mumbai 40012, India

e-mail: jdivatia@yahoo.com

Tel.: +91-98-69077435

Fax: +91-22-24146937

S. Jog

Deenanath Mangeshkar Hospital and Research Center,

Pune, India

It is indeed an honour for an Indian to be represented on the Editorial Board of a journal of the stature and caliber of Intensive Care Medicine. One of the responsibilities of the International Editor is to attract the best research in critical care in India to be published in the journal. The magnitude of the task at hand is evident when a search of the SCOPUS database since 1977 revealed only 72 articles from India published in three major critical care journals, of which 32 were in Intensive Care Medicine. This is despite the vast pool of clinical expertise and experience available in the country, and English being the medium of instruction for all medical education. How can we increase the contribution of Indian research and data on the global stage? What are the strengths that we can exploit and the weaknesses we need to overcome? Perhaps a look into the evolution of intensive care medicine in India [1] can provide some answers.

Intensive care medicine is a relatively new specialty in India. Indeed, modern critical care in India has a history of only approximately 20 years. Before this, critical care was practised in a few hospitals, either by those interested in the field and learning on the job, or by doctors returning to India after training overseas. The turning point in history was the formation of the Indian Society of Critical Care Medicine (ISCCM) on October 9, 1993. The ISCCM has grown into one of the largest and finest professional organisations with a membership of over 6,500, and serves as a catalyst for education and training in CCM in India. A major challenge initially was the development of trained manpower, as intensive care medicine was not recognised as a speciality by the Medical Council of India (MCI), the apex body for accreditation of postgraduate medical education in India. To overcome this lacuna, the ISCCM introduced a 1-year training programme, the Indian Diploma in Critical Care (IDCC) in 1996, along the lines of the European Diploma in Intensive Care (EDIC) [2]. A 2-year programme, the Indian Fellowship in Critical Care (IFCC), was introduced in 2007. Through the last 15 years, 126 intensive care units (ICUs) have been accredited for the ISCCM courses (Fig. 1) and more than 400 doctors have been trained, with more than 60 intensivists currently graduating every year. This growing pool of trained intensivists will eventually contribute to various research activities.

In 2012, critical care was recognized as an independent speciality by the MCI, enabling 3-year training programmes after a postgraduate base specialisation leading to a university degree in critical care. This will facilitate the development of academic departments of intensive care medicine with greater emphasis on research, and we can look forward to more high quality publications in the near future.

The majority of ICU beds in India are in private hospitals, where the focus is on providing revenue-generating critical care services rather than research and publication. Public hospitals, including university-affiliated teaching hospitals, constitute a small minority of the critical care beds in India. In these hospitals, facilities to carry out 


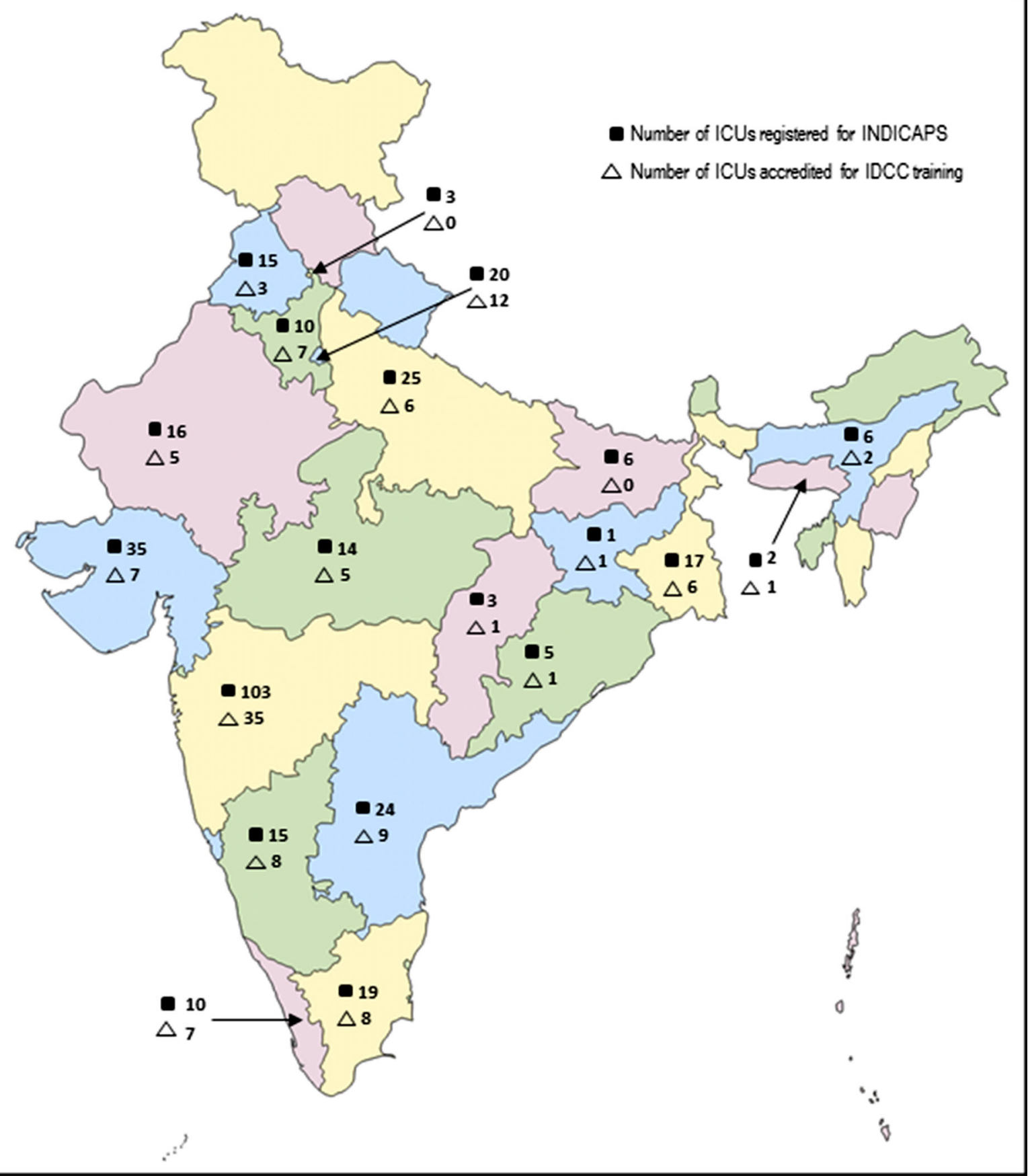

Fig. 1 India with state boundaries. Solid squares represent the number of hospital ICUs registered for INDICAPS (Indian Intensive Care Case Mix and Practice Patterns Study) in each

quality research are quite limited. Despite these apparent limitations, India has participated in and made significant contributions to large multicentre randomised controlled trials including the PROWESS-SHOCK [3] and state. Not all ICUs that registered for the study contributed patient data. Open triangles are the number of ICUs accredited for the Indian Diploma in Critical Care (IDCC) in each state

OSCILLATE studies [4] and a number of international, multicentre observational studies [5-9].

The critical care community in India is acutely aware that research relevant to Indian circumstances is essential 
for further progress of intensive care medicine in India. The Indian Intensive Care Case Mix and Practice Patterns Study (INDICAPS), a staggered 4-day point prevalence study aimed at collecting vital data on patients and practices in Indian ICUs, has been completed, recruiting 4,038 adult patients in 124 ICUs (Fig. 1). A prospective multicentre observational study of nosocomial infections (MOSER) in 17 ICUs has also been completed. The Research Committee of the ISCCM is currently engaged in a prospective study of tropical infections in ICUs. We hope to publish the results of these studies in high-impactfactor journals such as Intensive Care Medicine.

There was a $35 \%$ increase in the number of abstract submissions at the Annual Conference of the ISCCM in 2013 compared to the 2012 conference (180 vs. 133). Twenty-five Indian abstracts were presented at the European Society of Intensive Care Medicine Congress in 2013. However, the publication rate in international journals has been very low [10]. Rejection of manuscripts at peer review could certainly be a major reason, but perhaps time constraints and lack of motivation to publish were important contributing factors.

Thus, there is a strong commitment to research in Indian critical care. Our strengths include a huge knowledge-base for tropical and infectious diseases [11, 12], large patient numbers, a philosophical background in endof-life care issues $[13,14]$ and cost-effectiveness strategies, combined with strong information technology support to develop innovative solutions [15] to many critical care problems.

The challenge is to translate presentations into publications. The Indian Journal of Critical Care Medicine was indexed in PubMed in 2010, and recently, the Indian Journal of Anaesthesia and the Journal of Anaesthesiology Clinical Pharmacology, journals that publish articles related to critical care, have also been indexed in PubMed. This will undoubtedly allow Indian authors and publications to reachout globally and encourage and motivate authors to publish their studies and data. Similarly, publication of a few high-quality manuscripts in journals such as Intensive Care Medicine will inspire confidence to send the best research to this journal.

Intensivists in India have a high regard for European intensive care. European intensivists are highly acclaimed and respected speakers at our national meetings. The journal Intensive Care Medicine is also popular as it is seen to publish more human clinical research than experimental and laboratory medicine. With increasing interest in clinical research in India, greater determination and opportunities to pursue high-quality research in India, and a willingness to share and contribute the vast clinical data available to multicentre studies, Indian intensive care is poised for greater engagement with European critical care, including in Intensive Care Medicine.

Conflicts of interest On behalf of all authors, the corresponding author states that there is no conflict of interest.

\section{References}

1. Prayag S (2002) ICUs worldwide: critical care in India. Crit Care 6:479-480

2. http://isccm.org/Edu_Course_IDCCM_ Duration.htm. Accessed October 312013

3. Ranieri VM, Thompson BT, Barie PS et al (2012) Drotrecogin alfa (activated) in adults with septic shock. N Engl J Med 366:2055-2064

4. Ferguson ND, Cook DJ, Guyatt GH et al (2013) High-frequency oscillation in early acute respiratory distress syndrome. N Engl J Med 368:795-805

5. Vincent JL, Rello J, Marshall J et al (2009) International study of the prevalence and outcomes of infection in intensive care units. JAMA 302:2323-2329

6. Mehta Y, Jaggi N, Rosenthal VD et al (2013) Effectiveness of a multidimensional approach for prevention of ventilator-associated pneumonia in 21 adult intensive-care units from 10 cities in India: findings of the International Nosocomial Infection Control Consortium (INICC). Epidemiol Infect 141:2483-2491
7. Phua J, Koh Y, Du B et al (2011) Management of severe sepsis in patients admitted to Asian intensive care units: prospective cohort study. BMJ. doi: 10.1136/bmj.d3245

8. Esteban A, Frutos-Vivar F, Muriel A et al (2013) Evolution of mortality over time in patients receiving mechanical ventilation. Am J Respir Crit Care Med 188:220-230

9. Vincent JL, Sakr Y, ICON investigators (2013) The Intensive Care Over Nations (ICON) audit: epidemiology of sepsis. Intensive Care Med 39:S229

10. Tyagi A, Chugh V, Kumar S, Sethi AK (2013) Presentation of research in anesthesia: culmination into publication? J Anaesthesiol Clin Pharmacol 29:216-220

11. Jog S, Patel D, Dravid T et al (2013) Early application of high frequency oscillatory ventilation in ' $\mathrm{H} 1 \mathrm{~N} 1$ influenza' related ARDS is associated with better outcome: a retrospective study. Intensive Care Med 39:1146-1147
12. Khilnani P, Sarma D, Zimmerman J (2006) Epidemiology and peculiarities of pediatric multiple organ dysfunction syndrome in New Delhi, India. Intensive Care Med 32:1856-1862

13. Mani RK, Amin P, Chawla R et al (2012) Guidelines for end-of-life and palliative care in Indian intensive care units: ISCCM consensus Ethical Position Statement. Indian J Crit Care Med 16:166-181

14. Mani RK, Mandal AK, Bal S et al (2009) End-of-life decisions in an Indian intensive care unit. Intensive Care Med 35:1713-1719

15. Chacko J, Nikahat J, Gagan B et al (2012) Real-time ultrasound-guided percutaneous dilatational tracheostomy. Intensive Care Med 38:920-921 